\title{
Contrasting plasma free amino acid patterns in elite athletes: association with fatigue and infection
}

\author{
K J Kingsbury, L Kay, M Hjelm
}

\begin{abstract}
Aim-There is little information on the plasma free amino acid patterns of elite athletes against which fatigue and nutrition can be considered. Therefore the aim was to include analysis of this pattern in the medical screening of elite athletes during both especially intense and light training periods.
\end{abstract}

Methods-Plasma amino acid analysis was undertaken in three situations. (1) A medical screening service was offered to elite athletes during an intense training period before the 1992 Olympics. Screening included a blood haematological/ biochemical profile and a microbial screen in athletes who presented with infection. The athletes were divided into three groups who differed in training fatigue and were considered separately. Group A (21 track and field athletes) had no lasting fatigue; group $B$ (12 judo competitors) reported heavy fatigue at night but recovered overnight to continue training; group C (18 track and field athletes, one rower) had chronic fatigue and had been unable to train normally for at least several weeks. (2) Athletes from each group were further screened during a post-Olympic light training period. (3) Athletes who still had low amino acid levels during the light training period were reanalysed after three weeks of additional protein intake.

Results-(1) The pre-Olympics amino acid patterns were as follows. Group $A$ had a normal amino acid pattern (glutamine 554 (25.2) $\mu \mathrm{mol} / 1$, histidine 79 (6.1) $\mu \mathrm{mol} / 1$, total amino acids 2839 (92.1) $\mu \mathrm{mol} / 1)$; all results are means (SEM). By comparison, both groups $B$ and $C$ had decreased plasma glutamine (average $33 \%$; $\mathbf{p}<0.001$ ) with, especially in group $B$, decreased histidine, glucogenic, ketogenic, and branched chain amino acids $(p<0.05$ to $p<0.001$ ). None in group $A$, one in group $B$, but ten athletes in group $C$ presented with infection: all 11 athletes had plasma glutamine levels of less than $450 \mu \mathrm{mol} / 1$. No intergroup differences in haematological or other blood biochemical parameters, apart from a lower plasma creatine kinase activity in group $C$ than in group $B$ $(p<0.05)$ and a low neutrophil to lymphocyte ratio in the athletes with viral infections $(1.2(0.17))$, were found.

(2) During post-Olympic light training, group $A$ showed no significant amino acid changes. In contrast, group $B$ recovered normal amino acid levels (glutamine 528 (41.4) $\mu \mathrm{mol} / 1$, histidine 76 (5.3) $\mu \mathrm{mol} / 1$, and total amino acids 2772 (165) $\mu \mathrm{mol} / 1)$ $(p<0.05$ to $p<0.001)$ to give a pattern comparable with that of group $A$, whereas, in group $C$, valine and threonine had increased $(p<0.05)$, but glutamine $(441$ (24.5) $\mu \mathrm{mol} / 1)$ and histidine (58 (5.3) $\mu \mathrm{mol} / 1)$ remained low. Thus none in group $A$, two in group $B$, but ten (53\%) in group C still had plasma glutamine levels below $450 \mu \mathrm{mol} / 1$, including eight of the 11 athletes who had presented with infection.

(3) With the additional protein intake, virtually all persisting low glutamine levels increased to above $500 \mu \mathrm{mol} / 1$. Plasma glutamine rose to 592 (35.1) $\mu \mathrm{mol} / 1$ and histidine to $86(6.0) \mu \mathrm{mol} / 1$. Total amino acids increased to 2761 (128) $\mu \mathrm{mol} / 1$ $(p<0.05$ to $p<0.001)$ and the amino acid pattern normalised. Six of the ten athletes on this protein intake returned to increased training within the three weeks. Conclusion-Analysis of these results provided contrasting plasma amino acid patterns: (a) a normal pattern in those without lasting fatigue; (b) marked but temporary changes in those with acute fatigue; (c) a persistent decrease in plasma amino acids, mainly glutamine, in those with chronic fatigue and infection, for which an inadequate protein intake appeared to be a factor.

\section{(Br F Sports Med 1998;32:25-33)}

Keywords: elite athletes; plasma amino acids; glutamine; fatigue; infection; protein intake

It is known that prolonged exercise causing fatigue can increase overall protein catabolism and reduce the plasma and muscle content of amino acids with different metabolic functions. ${ }^{1-3}$ Various studies have reported changes in the plasma free amino acid levels during and after exercise. ${ }^{2-8}$ Decreased plasma glutamine has been found in athletes with the "overtraining" syndrome. ${ }^{610}$ There have been suggestions that infection in athletes may be associated with changes in plasma amino acid levels ${ }^{610}$ and that these levels are transiently altered by consumption of meals of different protein contents. ${ }^{11}$ However, there is little information on the plasma free amino acid pattern of elite athletes against which fatigue, infection, and nutrition can be considered.

Plasma free amino acid analysis was therefore included in a medical screening service offered to elite athletes in an especially intense training period before the 1992 Olympics.
Accepted for publication 31 October 1997 
Screening included a blood haematological/ biochemical profile and a standard microbial screen in athletes presenting with infection. Three groups clearly differing in training fatigue were considered separately: group A (track and field athletes) had no lasting fatigue; group B (judo players) suffered heavy fatigue at night but recovered overnight to continue training; group $\mathrm{C}$ (track and field athletes and one rower) had chronic fatigue and had been unable to train normally for at least several weeks.

Medical screening after the Olympics included athletes from each group during a winter light training period. Athletes who still showed low plasma amino acid levels were advised to consume extra protein and were reanalysed after three weeks.

We here report the pre-Olympic plasma amino acid patterns and infection in these three groups, the patterns during post-Olympic light training, and the effect of the recommended protein supplement.

\section{Methods}

MEDICAL SCREENING AND INVESTIGATION

Medical screening was set up at the request of elite athletes as a check on their medical condition during an intense pre-Olympic training period. Screening comprised: $(a)$ a standard medical examination including urine "Multistix" test ( $\mathrm{pH}$, specific gravity, glucose, protein, blood, ketones, urobilinogen, and bilirubin), body weight, and body fat percentage by caliper $^{12} ;(b)$ a standard blood sampling in the morning after an overnight fast by venepuncture without stasis into chilled vacuum tubes and immediate standard separation of plasma; (c) a haematological/biochemical profile, plus a throat swab (aerobic/anaerobic culture), urine microscopy/culture, and a standard blood microbiological investigation (glandular fever screen, antibodies for 13 viruses, coxsackie B1-5, mycoplasma, and toxoplasma) in athletes presenting with infection (MDL laboratory, London). The results were reported to the athletes, and those with infection were monitored until recovery. Where appropriate, antibiotics were given by the athlete's doctor.

For amino acid analysis, heparinised plasma obtained as above was kept chilled and stored at $-20^{\circ} \mathrm{C}$ within a few hours and analysed within a few days. Pilot studies showed that this procedure did not alter the plasma amino acid levels. Amino acids were analysed by high pressure liquid chromatography (HPLC) with phenylisothiocyanate derivatisation ${ }^{13}$ (Amino Acid Analysis Reference Laboratory, Great Ormond Street Hospital, London, UK). This gave a close correspondence to results using ion exchange chromatography. ${ }^{13}$ Reference ranges taken from large groups of hospital patients $(\mathrm{MH})$ covered the similar resting plasma amino acid values found in metabolically healthy adults by ion exchange chromatography, ${ }^{2} 35111415$ enzymatic assay, ${ }^{6}$ and HPLC. ${ }^{7}$
ATHLETES

The athletes were not selected but were those who requested medical screening during this period. Fatigue and infection at screening were ascertained from the medical examination/ history and checked with the athletes and coaches. The athletes were divided into three groups. Group A consisted of 11 female and 10 male international field and track athletes (seven sprinters, 11 middle distance runners, two "throwers", one heptathlete); they felt well and had no lasting fatigue. Group B was made up of 12 international female judo competitors (screened towards the end of an unusually heavy training period); they felt well but reported heavy fatigue at night after the day's training; however, they recovered overnight to continue their usual training. Group C consisted of 15 female and four male international competitors (five sprinters, 11 middle distance runners, one "jumper", one "thrower", one rower); they had chronic fatigue and had been unable to train normally, even with rest days, for 3-16 weeks. All athletes kept detailed training diaries. From these diaries, the athletes in group $\mathrm{C}$ reported an inability to undertake the same intensity or degree of exercise, higher pulse rates in equivalent exercise, and a poorer performance than before their fatigue. Broad dietary preferences were obtained at screening. The athletes, in general, consumed a high carbohydrate diet. There was one vegetarian in group $\mathrm{A}$, none in group $\mathrm{B}$, and one in group $\mathrm{C}$. Nine others in group C, one other in group A, and one in group B severely restricted dairy produce and animal protein. Mean (SEM) ages (years) were: group A, 25.6 (1.27); group B, 23.2 (1.06); group C, 25.4 (0.75); middle distance runners in group A, 25.3 (1.8); middle distance runners in group C, 25.7 (1.6).

TRAINING

From their detailed training diaries, all athletes completed a questionnaire on the type and duration of their training on the day before screening. Daily training (hours) had been: group A, 2.5-4.5 (long/interval runs, circuits, skills of varied intensity); group B, 4.0-6.5 (long/interval runs, circuits, weights, skills and pressurised judo/uchikomi); group C, 0-1.5 (varied, easy training). None had competed in the preceding week. Although divided into weight categories, all subjects in group B were training at a comfortable training weight.

REANALYSIS DURING LIGHT TRAINING

Medical screening was further offered to elite athletes after the Olympics so that abnormalities could be corrected before the next competitive season. This included screening 16 of group A, eight of group B, 15 of group C (with seven middle distance runners from group A and eight from group C) during light winter training six or seven months after their initial screening. Obtained as above, by questionnaire, training (hours) on the day before screening was: group A, 1-2.5 (varied, often including runs); group B, 1.5-3.5 (varied, usually including judo); group C, 0.5-2.5 (varied, often including a steady run). All groups 
Table 1 Mean (SEM) plasma free amino acid levels of the athlete groups before and after the Olympics

\begin{tabular}{|c|c|c|c|c|c|c|c|}
\hline \multirow[b]{3}{*}{ Amino acid } & \multicolumn{7}{|c|}{ Amino acid level $(\mu \mathrm{mol} / \mathrm{l})$} \\
\hline & \multirow[b]{2}{*}{ Normal range } & \multicolumn{3}{|l|}{ Pre-Olympic } & \multicolumn{3}{|l|}{ Post-Olympic } \\
\hline & & $A$ & $B$ & $C$ & $A$ & $B$ & $C$ \\
\hline Glutamine & $480-800$ & $554(25.2)$ & $356(16.0)^{\star \star \star}$ & $383(13.6)^{\star \star \star}$ & $541(22.6)$ & $528(41.4)+\dagger+$ & $441(24.5) \dagger$ \\
\hline Histidine & $30-150$ & $79(6.1)$ & $32(1.2)^{\star \star \star}$ & $50(2.9)^{\star \star \star}$ & $82(4.5)$ & 76 (5.3)t+† & $58(5.3)$ \\
\hline Alanine & $150-450$ & $422(24.7)$ & $352(20.4)^{\star}$ & $344(17.1)^{\star}$ & $352(31.6)$ & $397(41.8)$ & $325(20.0)$ \\
\hline Threonine & $70-220$ & $121(8.7)$ & $72(4.7)^{\star \star \star}$ & $91(4.6)^{\star \star}$ & $128(9.8)$ & $110(7.5)++\dagger$ & $116(9.1) \dagger$ \\
\hline Serine & $90-290$ & $104(5.3)$ & $109(5.3)$ & $88(5.1)^{\star}$ & $104(7.4)$ & $119(8.8)$ & $104(8.0)$ \\
\hline Lysine & $100-300$ & $161(8.5)$ & $89(6.1)^{\star \star \star}$ & $124(8.2)^{\star \star}$ & $148(14.7)$ & $142(7.4) \mathrm{tt \dagger}$ & $143(7.5)$ \\
\hline Tryptophan & $30-80$ & $67(3.5)$ & $44(3.7)^{\star \star \star}$ & $55(2.9)^{\star}$ & $66(4.1)$ & 59 (3.8)t† & $62(3.4)$ \\
\hline Tyrosine & $30-120$ & $62(3.8)$ & $43(3.2)^{\star \star \star}$ & $55(4.3)$ & $56(4.3)$ & $56(3.8) \dagger$ & $62(2.6)$ \\
\hline Valine & $90-300$ & $219(11.4)$ & $151(8.8)^{\star \star \star}$ & $188(10.4)$ & $217(14.9)$ & $228(8.0)+t+$ & $225(2.6)+t$ \\
\hline Leucine & $65-220$ & $146(3.9)$ & $127(5.7)^{\star}$ & $137(9.5)$ & $140(10.9)$ & $138(5.1) \dagger \dagger$ & $146(10.1)$ \\
\hline Isoleucine & $26-100$ & $77(5.3)$ & $59(2.9)^{\star \star}$ & $69(4.6)$ & $70(8.1)$ & $71(5.6)$ & $68(4.5)$ \\
\hline Arginine & $40-120$ & $82(6.2)$ & $57(3.6)^{\star \star}$ & $71(4.9)$ & $77(6.0)$ & $74(5.7) \dagger$ & $80(7.9)$ \\
\hline Proline & $85-290$ & $232(12.1)$ & $196(13.8)$ & $188(18.7)$ & $208(19.2)$ & $245(12.3) \dagger$ & $191(14.0)$ \\
\hline Ornithine & $25-120$ & $59(3.9)$ & $58(5.3)$ & $60(5.5)$ & $61(6.76)$ & $69(7.8)$ & $59(6.5)$ \\
\hline Methionine & $10-60$ & $35(2.5)$ & $26(1.5)^{\star}$ & $30(1.3)$ & $30(2.2)$ & $31(2.1)$ & $34(2.8)$ \\
\hline Glutamic acid & $25-130$ & $55(6.3)$ & $102(4.9)^{\star \star \star}$ & $56(8.7)$ & $49(7.0)$ & $44(9.2)+t+$ & $53(7.0)$ \\
\hline Glycine & $100-330$ & $227(10.3)$ & $316(20.4)^{\star \star \star \star}$ & $199(9.9)$ & $236(17.2)$ & 238 (15.6) t+十 & $218(13.2)$ \\
\hline Phenylalanine & $35-100$ & $71(2.5)$ & $88(2.9)^{\star \star \star}$ & $70(4.1)$ & $60(3.4)$ & $68(8.0) t$ & $76(5.2)$ \\
\hline Taurine & $40-140$ & $67(5.4)$ & $119(5.1)^{\star \star \star}$ & $78(7.2)$ & $61(5.3)$ & $72(11.2) \dagger$ & $76(11.1)$ \\
\hline Total branched-chain & $(9-11)$ & $440(20.8)$ & $338(16.9)^{\star \star \star}$ & $388(21.6)$ & $433(30.6)$ & $432(18.3) \dagger$ & $436(19.2)$ \\
\hline Total amino acids & & $2839(92.1)$ & $2396(90.1)^{\star \star \star}$ & $2307(71.6)^{\star \star \star}$ & $2706(127.9)$ & $2772(165.4) \dagger$ & $2527(96.1)$ \\
\hline
\end{tabular}

${ }^{\star} \mathrm{p}<0.05 ;{ }^{\star \star} \mathrm{p}<0.01 ;{ }^{\star \star \star} \mathrm{p}<0.001$ compared with group A.

$t \mathrm{p}<0.05 ;+t \mathrm{p}<0.01 ;+\dagger+=\mathrm{p}<0.001$ compared with pre-Olympic value.

reported a much lower training intensity than competitive training.

ADDITIONAL PROTEIN INTAKE

The pre-Olympic results indicated that, of all the plasma amino acids investigated, glutamine showed the most marked changes. Athletes who persisted with glutamine levels below 450 $\mu \mathrm{mol} / 1$ during light training (two in group $\mathrm{B}$ and ten in group $\mathrm{C}$ ) were advised to maintain a high carbohydrate diet, but to consume additional protein (an average or larger helping of lean meat, fish, cheese, or soya), at least once on most days a week, and to supplement protein intake with skimmed milk powder in cereals and drinks. This advice was taken by the two athletes in group B and eight of the ten in group C. They were then reanalysed after three weeks. Standard food tables ${ }^{16-18}$ indicate that the protein supplement provided a minimum of 20-30 g protein a day. We felt that the athletes could maintain an unaccustomed diet for a three week period and that a rapid change in amino acid levels or condition in this time could be taken to result from the dietary change. Compliance and training were checked weekly by telephone. Compliance was excellent, as all athletes were eager to improve their condition. As controls, nine other elite athletes who did not change their diet (plasma glutamine, 402-566 $\mu \mathrm{mol} / \mathrm{l}$ ), and were first screened after the Olympics and reanalysed within nine months, showed no significant amino acid changes $(p>0.05)$ : initial glutamine 481 (15.4) $\mu \mathrm{mol} / \mathrm{l}$, repeat glutamine 469 (30.5) $\mu \mathrm{mol} / \mathrm{l}$.

ANALYSIS

Results are given as means (SEM). The pre-Olympic amino acid differences and the differences in other parameters between group $\mathrm{A}$ and groups $\mathrm{B}$ and $\mathrm{C}$ were evaluated by Student's $t$ test, as were the paired differences between the pre- and post-Olympic and the pre- and post-protein supplement samples.

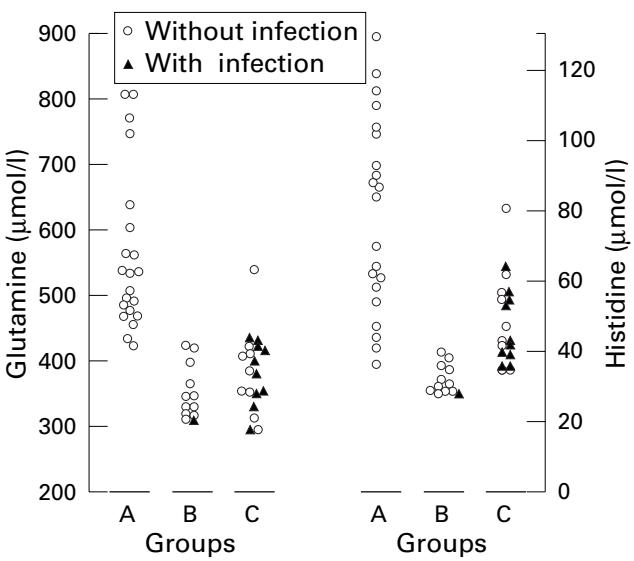

Figure 1 Pre-Olympic plasma glutamine and histidine levels ( $\mu \mathrm{mol} / \mathrm{l}$ ) in groups $A, B$, and $C$.

\section{Results}

PRE-OLYMPIC PLASMA AMINO ACID PATTERNS

Compared with group A (table 1), the two fatigued groups B and C showed a marked decrease in glutamine (average 33\%), histidine (average $43 \%$ ), and total amino acids (average $17 \%)(p<0.001)$. Some $10 \%$ of group A, but $100 \%$ of group B and $95 \%$ of group C had glutamine levels below $450 \mu \mathrm{mol} / 1$ (fig 1).

In addition, group $\mathrm{B}$ differed widely from group A, with lower levels of glucogenic amino acids (alanine and threonine), ketogenic amino acids (lysine, tryptophan, and tyrosine), all branched chain amino acids (valine, leucine, and isoleucine), and methionine and arginine $(\mathrm{p}<0.05$ to $\mathrm{p}<0.001)$, whereas four amino acids (glutamic acid, glycine, phenylalanine, and taurine) were higher than in group $A$ $(p<0.001)$. In contrast, group $C$ showed more selective changes. The decrease in plasma glutamine, alanine, serine, and total amino acids $(p<0.05$ to $p<0.001)$ was similar to those in group B. However, all other decreases were less marked, and there was no increase in any amino acid ( $\mathrm{p}>0.2)$. 


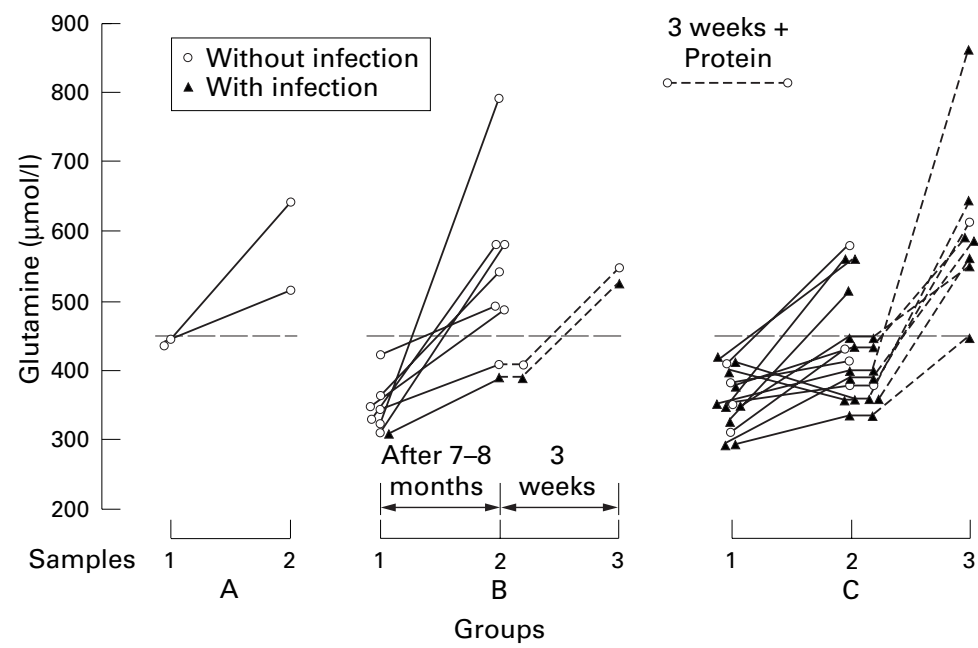

Figure 2 Plasma glutamine levels of athletes reanalysed in groups $A, B$, and $C$ who initially presented with glutamine levels below $450 \mu \mathrm{mol} / \mathrm{l}: 1$, initially; 2 , during light training; 3, after three weeks of the recommended additional protein intake.

Table 2 Mean (SEM) plasma free amino acid levels of athletes presenting without and with infection

\begin{tabular}{lrcr}
\hline \multicolumn{4}{c}{ Amino acid level $(\mu$ molll) } \\
\cline { 2 - 4 } Amino acid & Normal range & Without infection & With infection \\
\hline Glutamine & $480-800$ & $381(15.0)$ & $385(24.3)$ \\
Histidine & $30-150$ & $49(3.3)$ & $51(4.9)$ \\
Alanine & $150-450$ & $339(22.4)$ & $347(27.2)$ \\
Threonine & $70-220$ & $88(6.9)$ & $95(6.0)$ \\
Serine & $90-290$ & $85(6.2)$ & $91(8.4)$ \\
Lysine & $100-300$ & $113(11.2)$ & $135(11.4)$ \\
Tryptophan & $30-80$ & $58(4.0)$ & $52(4.7)$ \\
Tyrosine & $30-120$ & $59(7.8)$ & $53(3.1)$ \\
Valine & $90-300$ & $179(18.9)$ & $195(10.5)$ \\
Leucine & $65-220$ & $131(15.9)$ & $141(10.4)$ \\
Isoleucine & $26-100$ & $73(8.1)$ & $65(3.0)$ \\
Arginine & $40-120$ & $75(7.5)$ & $67(6.5)$ \\
Proline & $85-290$ & $183(17.9)$ & $191(11.7)$ \\
Ornithine & $25-120$ & $56(7.9)$ & $64(7.9)$ \\
Methionine & $10-60$ & $29(2.3)$ & $29(1.5)$ \\
Glutamic acid & $25-130$ & $49(4.5)$ & $61(9.0)$ \\
Glycine & $100-330$ & $197(16.0)$ & $204(11.9)$ \\
Phenylalanine & $35-100$ & $69(6.5)$ & $70(5.0)$ \\
Taurine & $40-140$ & $82(8.2)$ & $76(13.1)$ \\
\hline
\end{tabular}

Table 3 Mean (SEM) plasma free amino acid levels of athletes before and after the additional protein intake

\begin{tabular}{llll}
\hline Amino acid & Normal range & Before extra protein & After extra protein \\
\hline Glutamine & $480-800$ & $378(12.6)$ & $592(35.1)^{\star \star \star}$ \\
Histidine & $30-150$ & $49(5.0)$ & $86(6.0)^{\star \star \star}$ \\
Alanine & $150-450$ & $319(23.5)$ & $395(19.6)^{\star}$ \\
Threonine & $70-220$ & $102(11.8)$ & $136(8.4)^{\star}$ \\
Serine & $90-290$ & $102(12.3)$ & $102(7.0)$ \\
Lysine & $100-300$ & $129(10.5)$ & $142(16.2)$ \\
Tryptophan & $30-80$ & $58(3.6)$ & $67(5.9)$ \\
Tyrosine & $30-120$ & $57(3.4)$ & $61(6.8)$ \\
Valine & $90-300$ & $193(11.1)$ & $225(15.6)$ \\
Leucine & $65-220$ & $149(11.6)$ & $129(13.2)$ \\
Isoleucine & $26-100$ & $66(5.5)$ & $61(7.8)$ \\
Arginine & $40-120$ & $77(10.0)$ & $102(11.7)$ \\
Proline & $85-290$ & $181(11.7)$ & $231(26.4)$ \\
Ornithine & $25-120$ & $45(4.4)$ & $48(6.3)$ \\
Methionine & $10-60$ & $30(2.2)$ & $37(4.9)$ \\
Glutamic acid & $25-130$ & $65(6.8)$ & $31(4.5)^{\star \star \star}$ \\
Glycine & $100-330$ & $214(17.7)$ & $201(26.7)$ \\
Phenylalanine & $35-100$ & $82(5.1)$ & $62(5.6)^{\star}$ \\
Taurine & $40-140$ & $86(7.8)$ & $54(9.7)^{\star}$ \\
Total branched chain & & $136(11.2)$ & $138(14.3)$ \\
Total amino acids & & $2379(88.8)$ & $2761(128.2)^{\star}$ \\
\hline
\end{tabular}

${ }^{\star} \mathrm{p}<0.05,{ }^{\star \star} \mathrm{p}<0.01,{ }^{\star \star \star} \mathrm{p}<0.001$ compared with value before extra protein intake.

AMINO ACID PATTERNS DURING POST-OLYMPIC LIGHT TRAINING

The groups also differed during light training (table 1). Group A showed no significant amino acid changes. In contrast, in group B all previously low amino acid levels were increased. In particular, most of group B showed a substantial increase in glutamine, by an average of $48 \%$, from the initially low levels of less than $450 \mu \mathrm{mol} / 1$ in $100 \%$ of this group (figs 1 and 2). There was also a large increase in histidine (by 56\%) and an increase in total amino acids (by 16\%). The statistical significance for all these changes was $p<0.05$ to $p<0.001$. In addition, all raised amino acid levels in group $B$ were decreased $(\mathrm{p}<0.05$ to $\mathrm{p}<0.001)$ to give a total pattern comparable with that of group A. In group $\mathrm{C}$, on the other hand, plasma valine increased by $16 \%(\mathrm{p}<0.01)$, but there was only a slight rise in the levels of the other amino acids $(\mathrm{p}<0.05)$. Plasma glutamine (441 (24.5) $\mu \mathrm{mol} / \mathrm{l})$ and histidine $(58$ (5.3) $\mu \mathrm{mol} / \mathrm{l})$ remained low. Thus none in group $\mathrm{A}$, two in group B, but ten $(53 \%)$ in group $C$ still had plasma glutamine levels below $450 \mu \mathrm{mol} / 1$ (fig 2 ): seven of these 12 athletes were known to restrict dietary dairy produce and animal protein.

ASSOCIATED INFECTION

Ten athletes in group C (53\%) presented with infection at screening (two sprinters, five middle distance runners, one jumper, one thrower, one rower) compared with none in group $A$ and none in group B; however, one in group B developed glandular fever within six weeks (fig 1). In all these 11 athletes, symptoms including fatigue had lasted over three weeks. The type of infection was ascertained from positive cultures or raised antibody litres. The 11 infections were: two streptococcal throats, three glandular fevers, two Epstein Barr, one enterovirus, one parvovirus, one adenovirus, and one mycoplasma pneumonia. In all 11 athletes, symptoms of infection abated within two months. Fatigue inhibiting training persisted after the Olympics in nine of the 12 athletes with continuing low amino acid levels (five previously with and four without infection).

Group C showed no significant amino acid differences between those with and without infection ( $p>0.1$; table 2$)$. However, all 11 athletes presenting with infection had plasma glutamine levels below $450 \mu \mathrm{mol} / 1$ (fig 1), and eight (seven in group $\mathrm{C}$ and the one in group B) still had such levels after the Olympics (fig 2).

ADDITIONAL PROTEIN INTAKE

With this three week additional protein intake (table 3), there was a substantial increase in glutamine (by 57\%) and histidine (by $76 \%$ ) and a substantial decrease in glutamic acid (by $52 \%)(\mathrm{p}<0.001)$. Alanine, threonine, and total amino acids increased $(\mathrm{p}<0.05)$, while phenylalanine and taurine decreased $(p<0.05)$ to give a normal amino acid pattern. Figure 2 shows that all persisting glutamine levels below 450 $\mu \mathrm{mol} / 1$, except one in group $\mathrm{C}$, had increased to above $500 \mu \mathrm{mol} / 1$ (average rise 52.9 (8.8)\%). Of the ten athletes consuming this additional protein, six reported that they had been able to increase their intensity of training within the three weeks. 
Table 4 Mean (SEM) plasma amino acids in middle distance runners of groups $A$ and $C$ showing significant changes either pre-or post-Olympics or with the additional protein intake

\begin{tabular}{|c|c|c|c|c|c|c|c|}
\hline \multirow[b]{3}{*}{ Amino acid } & \multicolumn{7}{|c|}{ Amino acid level $(\mu \mathrm{mol} / \mathrm{l})$} \\
\hline & \multirow{2}{*}{$\begin{array}{l}\text { Normal } \\
\text { range }\end{array}$} & \multicolumn{2}{|l|}{1} & \multicolumn{2}{|l|}{2} & \multicolumn{2}{|l|}{3} \\
\hline & & $A(11)$ & $C(11)$ & $A(7)$ & $C(8)$ & Before (4) & After (4) \\
\hline Glutamine & $480-800$ & $569(38.6)$ & $383(20.7)^{\star \star \star}$ & $575(18.7)$ & $450(36.7)$ & $364(12.3)$ & $532(32.3)$ \\
\hline Histidine & $30-150$ & $78(8.9)$ & $48(3.1)^{\star \star}$ & $83(8.4)$ & $56(8.9)$ & $46(8.4)$ & $92(10.7)$ \\
\hline Alanine & $150-450$ & $431(28.2)$ & $323(23.7)^{\star}$ & $361(39.3)$ & $329(37.8)$ & $278(26.7)$ & $388(19.7)$ \\
\hline Threonine & $70-220$ & $116(10.6)$ & $85(5.8)^{\star}$ & $130(12.7)$ & $117(15.6)$ & $108(18.8)$ & $141(15.3)$ \\
\hline Serine & $90-290$ & $106(7.1)$ & $85(6.6)^{\star}$ & $110(13.8)$ & $98(11.0)$ & $84(11.8)$ & $103(11.4)$ \\
\hline Lysine & $100-300$ & $156(8.4)$ & $129(7.8)^{\star}$ & $121(9.2)$ & $142(12.3)$ & $136(20.7)$ & $137(19.0)$ \\
\hline Tryptophan & $30-80$ & $70(4.4)$ & $55(4.4)^{\star}$ & $65(5.1)$ & $67(4.2)$ & $67(5.4)$ & $68(7.0)$ \\
\hline Valine & $90-300$ & $215(18.5)$ & $195(15.6)$ & $203(16.2)$ & $224(17.5)$ & $184(24.0)$ & $223(7.0)$ \\
\hline Glutamic acid & $25-130$ & $45(7.3)$ & $50(8.3)$ & $47(8.7)$ & $63(9.6)$ & $56(4.1)$ & $38(5.2)$ \\
\hline Phenylalanine & $35-100$ & $73(3.5)$ & $74(5.8)$ & $53(3.6)$ & $73(8.5)$ & $77(4.6)$ & $52(6.1)$ \\
\hline $\begin{array}{l}\text { Total branched } \\
\text { chain }\end{array}$ & & $429(33.8)$ & $358(18.6)$ & $405(35.9)$ & $411(32.7)$ & $382(45.1)$ & $401(19.5)$ \\
\hline $\begin{array}{l}\text { Total amino } \\
\text { acids }\end{array}$ & & $2815(131.0)$ & $2322(90.2)^{\star \star}$ & $2751(153.6)$ & $2509(178.3)$ & $2193(121.1)$ & $2710(133.4)$ \\
\hline
\end{tabular}

1. Pre-Olympics: significance of the differences between groups A and C. 2. Post-Olympics: significance of the paired differences between the corresponding initial and light training levels. 3. Before and after the additional protein intake.

${ }^{\star} \mathrm{p}<0.05,{ }^{\star \star} \mathrm{p}<0.01,{ }^{\star \star \star \star} \mathrm{p}<0.001$

With the small number (4) before and after additional protein, $t$ tests have to be viewed with caution but with this test the increase in glutamine ( $t 4.87)$, histidine $(t 3.37)$, and total amino acids $(t 2.81)$, and decrease in glutamic acid $(t 2.87)$ and phenylalanine $(t$ 3.20) were significant $(\mathrm{p}<0.05)$.

Note: valine and total branched chain acids are shown to contrast with the changes in other amino acids, e.g. glutamine, histidine, and total amino acids.

MIDDLE DISTANCE RUNNERS

For a specific within-sport comparison, table 4 compares the middle distance runners only of groups $\mathrm{A}$ and $\mathrm{C}$. As in the whole groups, those in group $\mathrm{C}$ showed: (a) a main pre-Olympic decrease in glutamine $(\mathrm{p}<0.001)$, histidine, and total amino acids $(\mathrm{p}<0.01) ;(b)$ poor postOlympic recovery; $(c)$ an increase in glutamine, histidine, and total amino acids with the additional protein intake $(\mathrm{p}<0.05$ to $\mathrm{p}<0.01)$.

OTHER PARAMETERS

We found two significant differences in other parameters. Before the Olympics, plasma creatine kinase activity (IU/l) measured at $37^{\circ} \mathrm{C}$ was lower in group C (215 (32)) than in group B (323 (27); p<0.05) (group A 271 (39)), but not after the Olympics when creatine kinase activity in group B decreased (group B, 176 (30); group C, 215 (32); group A, 198 (33)). The neutrophil to lymphocyte ratio was lower in the eight athletes with viral infections (1.2 (0.17)) than in either group A or group B $(1.8-2.0(0.17))$, or in those in group $C$ without infection $(2.1(0.26))(\mathrm{p}<0.05)$.

We found no significant pre- or postOlympic, intergroup difference in blood pressure, total white cell count, mean cell volume, serum iron, total protein, albumin, globulin, urea, glucose, calcium, magnesium, alkaline phosphatase, inorganic phosphate, bilirubin or, including the sexes separately, body fat percentage, plasma creatinine, uric acid, $\gamma$-globulin, blood haematocrit, haemoglobin, mean cell haemoglobin, or red cell count $(p>0.1)$. This also applied to: those with and without infection in group $\mathrm{C}$; the middle distance runners only in groups A and C; those with persisting low amino acid levels; the preand post-protein supplement samples. "Multistix" urine test was normal in all athletes.

WEIGHT CHANGES

From pre- to post-Olympic analysis, one athlete per group gained $2-3 \mathrm{~kg}$ and one lost 2 $\mathrm{kg}$. With the additional protein intake, two gained $1.5-2 \mathrm{~kg}$ and one lost $1.5 \mathrm{~kg}$; all other athletes had smaller weight changes. We found no relation between either body weight or body fat percentage and plasma glutamine level (regressions $\mathrm{p}>0.2$ ). These parameters are not considered further.

\section{Discussion}

Analysis of these athletes during an especially intense pre-Olympic training period and a post-Olympic light training period has provided contrasting plasma amino acid patterns: a normal pattern in those without lasting fatigue (group A), but wide amino acid changes in the two fatigued groups $\mathrm{B}$ and $\mathrm{C}$. Of the amino acids analysed, glutamine and to a lesser extent histidine showed the most consistent changes. Thus plasma amino acid levels in athletes of group A remained similar to those of other metabolically healthy adults shown by ion exchange chromatography, ${ }^{2} 35111415$ enzymatic assay, ${ }^{6}$ and HPLC, ${ }^{7}$ whereas athletes in groups $\mathrm{B}$ and $\mathrm{C}$ showed a marked decrease in glutamine and histidine, and these two amino acids showed near-parallel changes on reanalysis. Ornithine was the only amino acid to show no significant changes. An interesting finding is that the amino acid changes did not depend simply on the type of sport. Thus the subjects in groups A and C (both elite track and field athletes) had different plasma amino acid patterns throughout, as did the $52-58 \%$ of them who were middle distance runners. Group A and group B (judo competitors), on the other hand, had comparable post-Olympic amino acid patterns. Similar amino acid differences were obtained whether athletes with acute fatigue (group B) were compared with those in group A or with their own amino acid values during light training.

AMINO ACID CHANGES, FATIGUE, AND INFECTION One advantage of analysing a wide amino acid pattern is that, despite a similar pre-Olympic 
decrease in plasma glutamine, those with acute fatigue (group B) and chronic fatigue (group C) differed with respect to other amino acid changes, and, in group B, this supports a training effect. Thus decreased plasma ketogenic, glucogenic, and branched chain amino acids, as found in group B, have been found after other prolonged exhausting exercise. ${ }^{2-4}$ The muscle breakdown of branched chain acids is known to increase during exercise, ${ }^{19}{ }^{20}$ and a residual decrease in plasma amino acids was found 24 hours after a $100 \mathrm{~km}$ race. ${ }^{4}$ Unlike our results, increased plasma tyrosine $e^{421}$ and urea $^{421}$ has been found after prolonged exercise. In group B, it may be that any excess of plasma urea after training was excreted by the next day and that repetitive daily training had a greater catabolic effect. In fact, the preOlympic $34 \%$ fall in valine in group B, which was still evident overnight, at least equals that found after a $30 \mathrm{~km}$ cross country or marathon race $^{7}$ and after a four hour treadmill run when most plasma amino acids were decreased. ${ }^{2}$ Before the Olympics, athletes in group B also uniquely showed several raised amino acid levels. Although the mechanism of the raised levels is unclear, an obvious training effect is shown by the normalisation of all these levels during light training. In addition, a raised phenylalanine to tyrosine ratio after trauma has been taken as an indicator of a catabolic state. ${ }^{22}$ In group $\mathrm{B}$, the pre-Olympic ratio (2.1 (0.2)) was higher than the ratio during light training or in the other groups $(<1.33 \quad(<0.12)$; $\mathrm{p}<0.01)$. Moreover, increased plasma glutamic acid, phenylalanine, and taurine levels were found after a $100 \mathrm{~km} \mathrm{run},{ }^{4}$ and plasma phenylalanine was increased after a marathon race, ${ }^{7}$ in association with sepsis, ${ }^{23}$ and together with glycine for 10 days after elective cholecystectomy in metabolically healthy subjects. ${ }^{15}$

At the time screened, daily training in group $B$ had been unusually heavy even for normal precompetition training, which may account for the extensive amino acid changes. The marked fall in plasma histidine after such repetitive training is a new finding. Plasma histidine showed little change after a $100 \mathrm{~km}$ run, ${ }^{4}$ although a $17 \%$ decrease in plasma and muscle histidine was found after 10 minutes of bicycle exercise at $70 \%$ maximum oxygen uptake. ${ }^{5}$ However, a similar $32-34 \%$ fall in plasma glutamine was found for several days after 10 days of twice daily intense training in highly trained $\mathrm{men}^{8}$ and after a prolonged treadmill run. ${ }^{2}$ It is possible that daily prolonged intense training by the subjects in group $\mathrm{B}$ created a particular demand for glutamine. Renal extraction of plasma glutamine increases substantially in chronic metabolic acidosis when ammonia from deaminated glutamine serves to buffer hydrogen ions secreted into the renal tubules. ${ }^{24}{ }^{25}$ Moreover, a $30-40 \%$ fall in muscle glutamine ${ }^{2}$ or its precursors ${ }^{26}$ was found after intense ${ }^{26}$ or prolonged exercise. ${ }^{2}$ Although further study of such effects in high level training is needed, the post-Olympic recovery of both glutamine and histidine in the athletes in group B strongly suggests a training link.
In contrast, an outstanding feature of the athletes in group C was their decrease in plasma glutamine, both before and after the Olympics, despite greatly reduced training and the less marked changes in other amino acids. The degree of amino acid decrease in group $\mathrm{C}$ may result, in part, from severe competitive training before the fatigue started. Before and after the Olympics, however, the lack of training as in group B appears to be supported by the absence of a significant fall in branched chain amino acids and by the absence of any increase in amino acid levels. We have found no other report in athletes of a long term fall in plasma amino acids apparently not simply explained by training. However, athletes with the "overtraining" syndrome showed lower plasma glutamine than a control group matched as far as possible for training. ${ }^{6}$ Of 24 elite 100-200 m swimmers on the same four week training schedule, the eight finishing with symptoms of overtraining had shown lower plasma glutamine concentrations at two weeks. ${ }^{10}$

Other than a lower pre-Olympic plasma creatine kinase activity in group $\mathrm{C}$ than in group B, we found no intergroup difference in haematological or biochemical parameters apart from the amino acid changes. To our knowledge, no other report has examined a wide pathology in athletes with chronic fatigue but, although the amino acid pattern was not reported, decreased plasma glutamine was the only biochemical or haematological disorder found in ten athletes with symptoms of overtraining. ${ }^{9}$ Our findings in group C raise the question of whether the amino acid decrease itself correlated with the fatigue. ${ }^{9}$ In this respect, it is of interest that the amino acid changes in group $\mathrm{B}$, which recovered during light training, were not associated with chronic fatigue. In normal men, however, marked fatigue was found to be associated with a histidine deficient diet. ${ }^{27} \mathrm{~A}$ long term fall in muscle glutamine after elective surgery correlated with depressed protein synthesis, ${ }^{15} 28$ and after trauma has suggested intracellular muscle glutamine depletion which appeared to be prolonged by inadequate nutrition. ${ }^{22}$ Whether athletes such as those in group $\mathrm{C}$ have such abnormalities remains to be investigated.

Infection, in this study, also tended to be associated with a persistent decrease in plasma amino acids, mainly glutamine. Thus all 11 athletes presenting with infection had a plasma glutamine below $450 \mu \mathrm{mol} / 1$, and, despite recovery, eight $(73 \%)$ still had such levels after the Olympics. It is difficult to draw any conclusions about the incidence of infection since athletes who had felt unwell for some weeks would have tended to request screening and to present a prolonged infection. However, trained athletes, ${ }^{29}$ ultra-marathon ${ }^{30}$ and marathon runners, ${ }^{31}$ and both elite squash and hockey players ${ }^{32}$ have shown a raised incidence of upper respiratory tract infection. Athletes with symptoms of overtraining and decreased plasma glutamine gave a history of upper respiratory tract infection and gastrointestinal disorders. ${ }^{6}$ Conversely, in a four week training 
period, elite swimmers showed no relation between plasma glutamine level and upper respiratory tract infection, ${ }^{10}$ although glutamine levels estimated by bioassay were, in general, much higher than the similar levels found in elite athletes by enzymatic analysis ${ }^{6}$ and by HPLC in this study.

The reason for the present association between infection and amino acid reduction is unclear. We have no evidence that infection had affected the amino acid levels, since athletes with and without evident infection in group $\mathrm{C}$ had similar amino acid patterns. When patients with accidental trauma developed infection, there were no further changes in the plasma amino acid levels. ${ }^{22}$ However, in vitro studies of glutamine requirement have suggested that low glutamine levels as in group C may impair the function of human lymphocytes and other cells. ${ }^{6334}$ Decreased plasma glutamine has been found together with a reduced number of CD4 T blood cells or a decreased number or activity of blood lymphocyte killer cells after anaerobic training, ${ }^{35}$ a triathlon, ${ }^{36}$ or marathon race. ${ }^{37}$ The place of such changes in infection in athletes has yet to be reported, but $10 \mathrm{~g}$ oral glutamine given after an ultramarathon or marathon race was followed by a $40 \%$ reduction in the incidence of infection noted by the athletes in the subsequent week. ${ }^{38}$ It is also tempting to question whether a low plasma glutamine level as in group $\mathrm{C}$ is adequate for the reported glutamine requirement in gut mucosal health. ${ }^{39-41}$ The present results suggest that athletes with a persistent amino acid decrease, as observed in group C, could offer a basis for further study.

\section{ADDITIONAL PROTEIN INTAKE}

Our additional protein intake was recommended for athletes with persisting low amino acid levels, since over half (all but one in group C) were known to consume a high carbohydrate diet while restricting both dairy produce and animal protein. Although their precise diet was not known, the substantial increase in virtually all low glutamine levels, histidine, and total amino acids in those taking this supplement strongly suggests that these levels responded nutritionally and that previous protein intake had been inadequate. It is of interest that the additional protein largely increased the amino acid levels that were most reduced at the time and decreased other amino acids, in contrast with the transient rise in most plasma amino acids after a single protein meal. ${ }^{11}$ In contrast with our results, a four day increase in protein intake from $10 \%$ to $24 \%$ in six healthy men as part of an extreme dietary change $(82 \%$ carbohydrate and $8 \%$ fat to $3 \%$ carbohydrate and $72 \%$ fat) caused metabolic acidosis and decreased plasma and muscle glutamine, ${ }^{42}$ however, this differed completely from the present athletes who, in general, maintained a high carbohydrate diet.

To our knowledge, the effect of a protein supplement in athletes with persistent low amino acid levels has not been reported previously. However, several types of study suggest that the adequacy of protein intake in athletes needs further attention. For instance, protein catabolic studies during exercise have suggested that a primarily carbohydrate diet in athletes can lead to protein deficiency. ${ }^{43}$ In addition, nitrogen balance, ${ }^{44}$ obligatory nitrogen loss, ${ }^{45}$ and $\left[{ }^{14} \mathrm{C}\right]$ leucine studies ${ }^{19}$ have all questioned the adequacy of even the normally recommended "safe" protein intake for healthy young adults, even when energy requirements are adequately $\mathrm{met}^{44}$ and especially in exercise. ${ }^{19}$ Moreover, elite endurance athletes in maintenance training needed a "safe" intake of $1.6 \mathrm{~g}$ protein $/ \mathrm{kg}$ per day to maintain nitrogen balance, ${ }^{46}$ twice that advised for normal activities, ${ }^{47}$ which suggests that protein requirement may be even higher in competitive training. In addition, Lemon et $a l^{43}$ suggested that, even with an adequate overall dietary intake, particular amino acid deficiencies may arise.

It is of interest that we found no significant intergroup difference in plasma protein levels, even in the athletes with persisting low plasma amino acids (total protein 76 (0.9); albumin 44 (1.1), globulin $31(1.5) \mathrm{g} / \mathrm{l})$. Athletes with symptoms of overtraining and decreased plasma glutamine also showed normal serum albumin levels. ${ }^{9}$ In contrast, it is well established that plasma proteins can be decreased in protein-energy malnutrition. However, a low calorie $(1100 \mathrm{kcal})$, low protein diet ( $35 \mathrm{~g} /$ day) did not affect serum albumin level in either healthy young or elderly subjects, ${ }^{48}$ and it seems unlikely that any dietary protein inadequacy in the present athletes would have been more severe. Chronic fatigue in the present athletes followed an especially intense training period. Further study of the diet, fatigue, and plasma amino acid pattern and protein levels in elite athletes at different training levels is clearly needed. In this study, however, the rapid improvement in training of several athletes taking our recommended protein supplement supports the benefit of the additional protein and a link between their previous diet and fatigue.

In conclusion, analysis of a wide plasma amino acid pattern in the present athletes provided contrasting amino acid patterns: (a) a normal pattern in those without lasting fatigue; (b) marked although temporary amino acid changes associated with heavy acute fatigue; (c) a tendency for chronic fatigue and infection to be associated with a persistent decrease in amino acids, mainly glutamine. Our results support the view that dietary protein adequacy in high level exercise needs further study. ${ }^{19} 4346$

We are grateful to: Staff at MDL and Great Ormond Street Hospital laboratories, London, for technical assistance; the British Athletic Federation and British Judo Association for support and J Allison for co-ordination of the screening; J Anderson for data collation; the BMI, BUPA, Nuffield, and other hospitals around the United Kingdom in the athletes' localities for medical examination and blood sampling; World Courier for the stand-by collection and rapid transport of chilled blood/plasma in a special chiller cabinet; and Van den chilled blood/plasma in a special chiller cabinet; and Van den Bergh Foods Ltd for sponsorship of the amino acid analysis. In paper for their constructive help.

1 Lentner C, ed. Geigy scientific tables, 8th ed. 1986;4:3844,75-86,110-23,154-81.

2 Rennie MJ, Edwards RHT, Krywawych S, et al. Effect of Rennie MJ, Edwards RHT, Krywawych S, et al. Effect of
exercise on protein turnover in man. Clin Sci 1981;61:627exercise on protein turnover in man. Clin Sci 1981;61:627- 
3 Ahlborg G, Felig P, Hagenfeldt L, et al. Substrate turnover during prolonged exercise in Man $\mathcal{F}$ Clin Invest $1974 ; 53$. $1080-90$

4 Decombaz J, Reinhardt $\mathrm{P}$, Anantharaman $\mathrm{K}$, et al. Biochemical changes in a $100 \mathrm{~km}$ run: free amino acids, urea, and creatinine. Eur f Appl Physiol 1979;41:61-72.

5 Bergstrom J, Furst P, Hultman E. Free amino acids in muscle tissue and plasma during exercise in man. Clin Physiol 1985;5:155-60.

6 Parry-Billings M, Budget R, Koutedakis Y, et al. Plasma amino acid concentrations in the overtraining syndrome: possible effects on the immune system. Med Sci Sports Exer 1992;24:1353-8.

7 Blomstrand E, Hassen P, Ekblom B, et al. Administration of branched-chain amino acids during sustained exercise: effects on performance and on plasma concentrations of some amino acids. Eur F Appl Physiol 1991;63:83-8.

8 Keast D, Arstein D, Harper W, et al. Depression of plasma Keast D, Arstein D, Harper W, et al. Depression of plasma glutamine after exercise stress and its possible inf
the immune system. Med $\mathcal{F}$ Aust 1995;162:15-18

9 Rowbottom DG, Keast D, Goodman C, Morton AR. The haematological, biochemical and immunological profile of athletes suffering from the overtraining syndrome. Eur $f$ Appl Physiol 1995;70:502-9.

10 MacKinnon LT, Hooper SL. Plasma glutamine and upper respiratory tract infection during intensified training in swimmers. Med Sci Sports Exerc 1996;28:285-90.

11 Bergstrom J, Furst P, Vinnars E. Effect of a test meal, without and with protein, on muscle and plasma free amino acids. Clin Sci 1990;79:331-7.

12 Durnin JVGA, Wormsley J. Body fat assessed from total body density and its estimation from skinfold thickness: measurements on 481 men and women aged 16-72 years. Br f Nutr 1974;32:77-97.

13 Davey JF, Esser RS. Amino acid analysis of physiological fluids by high-performance liquid chromatography with phenylisothiocyanate derivatisation and comparison with phenylisothiocyanate derivatisation and comparison with ion-excha.

14 Elia M, Neale G, Livesy G. Alanine and glutamine release from human forearm; effects of glucose administration. Clin Sci 1985;69:123-33.

15 Petersson B, Vinnars E, Waller F-O, et al. Long-term changes in muscle free amino acid levels after elective abdominal surgery. Br $\mathcal{F}$ Surg 1992;79:212-1.

16 McCance RA, Widdowson EM. The composition of foods, 5 th ed. London: Royal Society of Chemistry, 1991:1-462.

17 McCance RA, Widdowson EM. The composition of foods, 4 th ed. 1st supplement. London: Royal Society of Chemistry, 1980:1-113.

18 Mills A, Patel S. Food portion sizes, 2nd ed. London: HMSO, 1994:1-102.

19 Hood DA, Terjung RL. Amino acid metabolism during exercise and following endurance training. Sports Med exercise and

20 Wagenmakers AJM, Brooks JH, Coakley JH, et al. Exerciseinduced activation of the branched-chain 2-oxo acid dehydrogenase in human muscle. Eur F Appl Physiol 1989;59: 159-67.

21 Haralambie G, Berg A. Serum urea and amino nitrogen changes with exercise duration. Eur F Appl Physiol 1976;36: 39-48.

22 Askanazi J, Carpenter YA, Michelson CB, et al. Muscle and plasma amino acids following injury: influence of intercurrent infection. Ann Surg 1980;192:78-86.

23 Roth E, Funovics J, Muhlbacher F, et al. Metabolic disorders in severe abdominal sepsis: glutamine deficiency in skeletal muscle. Clin Nutr 1982;1:25-41.

24 Curthoys NP, Watford M. Regulation of glutaminase activity and glutamine metabolism. Annu Rev Nutr 1995;15: $133-59$.

25 Welbourne TC, Joshi S. Interorgan glutamine metabolism during acidosis. FPEN $\mathcal{F}$ Parenter Enteral Nutr 1990;14:7785.

\section{Commentary}

This paper represents some original work that provides an important advance in our understanding of the relation between overtraining, infection, and plasma amino acid concentrations. The paper provides evidence that heavy training and overtraining can be distinguished on the basis of plasma amino acid patterns. One of the weaknesses of this study is that weighed food intakes were not obtained and so the link between diet (protein intake) and plasma amino acid levels necessarily has to remain speculative. The authors report various haematological variables, but it is surprising that measures of total and differential white blood cell counts were not made in view of the study's interest in the relation between infec-
26 Graham TE, Saltin B. Estimation of the mitochondrial Graham TE, Saltin B. Estimation of the mitochondrial
redox state in human skeletal muscle during exercise. 7 redox state in human skeletal

27 Kopple JD, Swendseid ME. Evidence that histidine is an essential amino acid in normal and chronically uremic man. F Clin Invest 1975;55:881-91.

8 Petersson B, Wernerman J, Waller S-O, et al. Elective abdominal surgery depresses muscle protein synthesis and increases subjective fatigue: effects lasting more than 30 days. Br F Surg 1990;77:796-800.

29 Douglas DJ, Hanson PG. Upper respiratory infections in the conditioned athlete. Med Sci Sports Exerc 1978;10:55.

30 Peters EM, Bateman ED. Ultramarathon running and upper respiratory tract infections. S Afr Med f 1983;64: $582-4$.

31 Nieman DC, Johanssen LM, Lee JW, et al. Infectious episodes in runners before and after the Los Angeles Marathon. F Sports Med Phys Fitness 1990;30:316-28.

32 Mackinnon LT, Ginn EM, Seymour GJ. Temporal relationship between decreased salivary IgA and upper respiratory tract infection in elite athletes. Aust $\mathcal{f}$ Sci Med Sport 1993;25:94-9.

33 Crawford J, Cohen HJ. The essential role of L-glutamine in lymphocyte differentiation in vitro. F Cell Physiol 1985;124 $275-82$

34 Smith RJ. Glutamine metabolism and its physiological importance. FPEN F Parenter Enteral Nutr 1990;14:40-4.

35 Hack V, Weiss C, Friedmann B, et al. Decreased plasm glutamine level and $\mathrm{CD}^{+}{ }^{+} \mathrm{T}$ cell number in response to 8 wk of anaerobic training. Am f Physiol 1997;272:E788-95.

36 Rohde T, MacLean DA, Hartkopp A, et al. The immune system and serum glutamine during a biathlon. Eur $7 \mathrm{Appl}$ Physiol 1996;74:428-34.

37 Castell LM, Poortmans JR, Leclerq R, et al. Some aspects of the acute phase response after a marathon race, and the effects of glutamine supplementation. Eur $\mathcal{F}$ Appl Physiol 1997;75:47-53.

38 Castell LM, Poortmans JR, Newsholme EA. Does glutamine have a role in reducing infections in athletes? Eur Appl Physiol 1996;73:488-90.

39 Souba WW, Klimberg VS, Plumley DA. The role of glutamine in maintaining a healthy gut and supporting the metabolic response to injury and infection. $\mathcal{F}$ Surg Res 1990;48:383-91.

40 Burke D, Alverdy JC, Aoys E, et al. Glutamine supplemented TPN improves gut immune function. Arch Surg 1989;124:1396-9.

41 van der Hulst RWJ, van Kreel BK, von Meyenfelds MF, et al. Glutamine and the preservation of gut integrity. Lancet 1993;341:1363-5.

42 Greenhaff PL, Gleeson M, Maughan RJ. The influence of an alteration in diet composition on plasma and muscle glutamine levels in man. Clin Sci 1988;74:20P.

43 Lemon POOR, Yarasheski KE, Dolny DG. The importance of protein for athletes. Sports Med 1984;1:474-84.

44 Garza C, Scrimshaw NS, Young VR. Human protein requirements: a long-term metabolic nitrogen balance study in young men to evaluate the $1973 \mathrm{FAD} / \mathrm{WHO}$ safe level of egg protein intake. F Nutr 1977;107:335-52.

45 Bodwell CE, Schuster EM, Kyle E, et al. Obligatory urinary and fecal nitrogen losses in young women, older men, and young men and the factorial estimation of adult human protein requirements. Am f Clin Nutr 1979;32:2450-9.

46 Tarnopolsky MA, MacDougall JD, Atkinson SA. Influence of protein intake and training status on nitrogen balance and lean body mass. $\mathcal{F}$ Appl Physiol 1988;64:187-93.

47 Department of Health, Report on Health and Social Subjects 41. Dietary reference values for food energy and mutrients for the United Kingdom. London: HMSO Fifth Impression 1992:78-84.

48 Rammohan M, Juan D. Effects of a low calorie, low protein diet on nutritional parameters, and routine laboratory values in nonobese young and elderly subjects. $\mathcal{F}$ Am Coll Nutr 1989;8:545-53.

tion, dietary protein intake, and plasma amino acid levels. It is well established that prolonged protein deficiency is associated with reduced white blood cell counts, reduced levels of plasma immunoglobulins, and an increased incidence of infection. The authors are aware that renal extraction of glutamine from plasma increases markedly during chronic metabolic acidosis. The reason is that most of this glutamine is deaminated and the ammonia secreted into the renal tubules where it serves to buffer hydrogen ions filtered and secreted into the tubules. About 30-70 $\mathrm{mmol}$ hydrogen ion is normally excreted as ammonium ion per day, but over $300 \mathrm{mmol}$ can be excreted after 3-4 days of chronic acidosis. ${ }^{1}$ Hence, it can be hypothesised that individuals engaged in daily bouts of high intensity exercise will be extract- 
ing large amounts of glutamine from the blood plasma, which may account for the low plasma glutamine concentrations observed. The effect of the dietary protein supplementation on the plasma glutamine concentration contrasts with the findings of Greenhaff et $a l^{2}$ who reported that four days on a low carbohydrate, high protein and fat diet caused a substantial fall in both plasma and muscle glutamine concentration (compared with a normal or high carbohydrate diet) in healthy humans. It should be noted that a high protein intake will induce a mild degree of metabolic acidosis, so athletes should be warned against taking excessive protein at the expense of reduced carbohydrate. The advice given by the authors to the athletes with low plasma glutamine concentrations to take an additional $20-30 \mathrm{~g}$ protein in addition to their normal (high carbohydrate diet) seems entirely appropriate.

M GLEESON

1 Simpson DP. Control of hydrogen ion homeostasis and renal acidosis. Medicine 1971;50:503-41.

2 Greenhaff PL, Gleeson M, Maughan RJ. The influence of an alteration in diet composition on plasma and muscle glutamine levels in man. Clin Sci 1988;74:20P.

\section{Sports medicine on the world wide web}

There are some excellent sports medicine sites on the world wide web. Over the past two years the web has expanded at an exponential rate, with hundreds of new sites coming on line every week. There is a vast encyclopaedia of information available to the home computer user. The biggest problem is knowing where to look, and an index or links page to your favourite topic can be invaluable.

The NSMI links page at http:// www.nsmi.org.uk/links.html is a useful start, and the NSMI have listed links to sports medicine organisations, journals and publishers, UK courses in sports medicine sciences, and search engines to sports medicine sites. Ideally a links page like this takes the work out of typing out full web addresses because the mouse pointer can be used to double click on a link which takes you directly to the page. Another sports medicine links page is MSPWEB sports medicine links at $h t t p: / /$ www.mspweb.com/orgs.html but most links are to web sites located outside the United Kingdom, mainly the USA. Other USA based links pages on sports medicine concentrate exclusively on US sites. I have been maintaining a sports medicine links page which concentrates on UK links and I will be developing a home page for BASM at the same site. The links page is at $h t t p: / /$ www. healthcentre.org. uk/hc/library/sports. htm.

Many of the USA sites are owned and operated by sports medicine physicians. They usually have areas where you can ask questions or download files on specific sports injuries, but they may expect you to give your credit card number before giving you access.
Personally I would not risk sending this sort of information over the internet. I prefer sites such as the FIMS home page http:// www.fims.org/. For governing body medical officers, the IOC medical code and current drugs list are available on line at $h t t p: / /$ www.olympic.org/emedical.html. The Gatorade sport science exchange page provides a useful collection of downloadable papers on sport medicine, mainly nutrition related, at http:// www.gssiweb.com/library/sse/index.html. For those interested in distance learning, the Centre for Continuing Education at Bath University provides details of its courses at http://www.bath.ac.uk/CCE/dl.html. The Scottish Institute of Sports Medicine and Sports Science at the University of Strathclyde gives details of its distance learning modules at http://www.strath.ac.uk/Departments/SISMSS/ modules.html. The USA based journal the Physician and Sportsmedicine at http:// www.physsportsmed.com/journal.htm is of good general interest, and the BJSM is at http:// www.bjsportmed.com.

The URLs (uniform resource locators) above are exactly as they appeared in my browser software, so if they don't work, check that you have typed them correctly. Some links may not work because the sites have moved to a different address. It is worth book marking working sites, as many offer links to new sports medicine pages as they come on line.

DAVID HUTCHINSON Antrim Health Centre 